\author{
M. A. D. Vente \\ T. C. de Wit \\ M. A. A. J. van den Bosch \\ W. Bult \\ P. R. Seevinck \\ B. A. Zonnenberg \\ H. W. A. M. de Jong \\ G. C. Krijger \\ C. J. G. Bakker \\ A. D. van het Schip \\ J. F. W. Nijsen
}

\section{Holmium-166 poly(L-lactic acid) microsphere radioembolisation of the liver: technical aspects studied in a large animal model}

Received: 2 April 2009

Revised: 13 August 2009

Accepted: 20 August 2009

Published online: 30 September 2009

(C) The Author(s) 2009.

This article is published with open access at

Springerlink.com

\section{A. D. Vente - T. C. de Wit .}

M. A. A. J. van den Bosch - W. Bult ·

H. W. A. M. de Jong

A. D. van het Schip .

J. F. W. Nijsen $(\bowtie)$

Department of Radiology and Nuclear

Medicine, University Medical Center

Utrecht,

P.O. Box 85500, 3508, GA,

Utrecht, The Netherlands

e-mail: f.nijsen@umcutrecht.nl

Tel.: +31-88-7556295

Fax: +31-30-2542531

P. R. Seevinck - C. J. G. Bakker Image Sciences Institute, University

Medical Center Utrecht,

Utrecht, The Netherlands

B. A. Zonnenberg

Department of Internal Medicine,

University Medical Center Utrecht,

Utrecht, The Netherlands

\section{G. C. Krijger}

Department of Radiation,

Radionuclides and Reactors, Faculty of

Applied Sciences, Delft University of

Technology,

Delft, The Netherlands

\begin{abstract}
Objective: To assess the accuracy of a scout dose of holmium-166 poly(L-lactic acid) microspheres ( ${ }^{166}$ Ho-PLLA-MS) in predicting the distribution of a treatment dose of ${ }^{166}$ Ho-PLLA-MS, using single photon emission tomography (SPECT). Methods: A scout dose $(60 \mathrm{mg})$ was injected into the hepatic artery of five pigs and SPECT acquired. Subsequently, a 'treatment dose' was administered (540 mg) and SPECT, computed tomography (CT) and magnetic resonance imaging (MRI) of the total dose performed. The two SPECT images of each animal were compared. To validate quantitative SPECT an ex vivo liver was instilled with ${ }^{166}$ Ho-PLLA-MS and SPECT
\end{abstract}

acquired. The liver was cut into slices and planar images were acquired, which were registered to the SPECT image. Results: Qualitatively, the scout dose and total dose images were similar, except in one animal because of catheter displacement. Quantitative analysis, feasible in two animals, tended to confirm this similarity $\left(r^{2}=0.34\right)$; in the other animal the relation was significantly better $\left(r^{2}=0.66\right)$. The relation between the SPECT and planar images acquired from the ex vivo liver was strong $\left(r^{2}=0.90\right)$. Conclusion: In the porcine model a scout dose of ${ }^{166}$ Ho-PLLA-MS can accurately predict the biodistribution of a treatment dose. Quantitative ${ }^{166} \mathrm{Ho}$ SPECT was validated for clinical application.

Keywords Holmium-166 . Yttrium-90 - Microspheres · Radioembolisation . Liver malignancies

\section{Introduction}

Intra-arterial radioembolisation with yttrium-90 microspheres $\left({ }^{90} \mathrm{Y}-\mathrm{MS}\right)$, either resin-based or with a glass matrix, is an increasingly applied treatment for patients with unresectable liver malignancies $[1,2]$. Efficacy of ${ }^{90} \mathrm{Y}$ radioembolisation relies on the difference in blood supply between liver malignancies and the normal liver parenchyma, which is predominantly arterial and mainly portal, respectively [3, 4]. This allows for the ${ }^{90} \mathrm{Y}-\mathrm{MS}$, when instilled into the hepatic artery, to target the tumours, consequently delivering high tumour absorbed doses whilst largely sparing the non-tumour-bearing liver tissue [1]. A critical component is the pretreatment procedure which consists of coeliac and superior mesenteric angiography and selective coiling of arteries supplying non-target organs such as the gastroduodenal artery and the right gastric artery, to ensure that the dose of ${ }^{90} \mathrm{Y}-\mathrm{MS}$ is 
implanted exclusively into the liver. To assess whether the coiling has been performed appropriately, technetium- $99 \mathrm{~m}$ albumin macroaggregates $\left({ }^{99 \mathrm{~m}} \mathrm{Tc}-\mathrm{MAA}\right)$ are injected into the hepatic artery. Subsequently, nuclear imaging is performed to determine whether extrahepatic deposition of the ${ }^{90} \mathrm{Y}-\mathrm{MS}$ should be expected and to calculate the lungshunt fraction [5-7]. The images are also used to predict the intrahepatic distribution of the ${ }^{90} \mathrm{Y}-\mathrm{MS}$ or, more specifically, the tumour-to-normal tissue ratio [8-10]. The ${ }^{99 \mathrm{~m}} \mathrm{Tc}-$ MAA are thus deployed as full surrogates for the ${ }^{90} \mathrm{Y}-\mathrm{MS}$. However, there are indications that this assumption is not justified as the reality is that the ${ }^{99 \mathrm{~m}}$ Tc-MAA image does not in all cases accurately correspond with the post- ${ }^{90} \mathrm{Y}-\mathrm{MS}$ infusion bremsstrahlung image. This is caused by differences in resolution between these images and also due to the overt differences in physical characteristics and in numbers of particles infused between the ${ }^{99 \mathrm{~m}} \mathrm{Tc}-\mathrm{MAA}$ and the ${ }^{90}$ Y-MS $[11,12]$ (Table 1). It has been demonstrated clinically that the intrahepatic uptake pattern of ${ }^{99 \mathrm{~m}} \mathrm{Tc}-$ MAA is not a strong predictor of tumour response after ${ }^{90} \mathrm{Y}$ radioembolisation [13].

Post-administration visualisation of the ${ }^{90} \mathrm{Y}$-MS is thus possible through bremsstrahlung single photon emission computed tomography (SPECT) imaging, but the quality is poor $[14,15]$. To overcome this lack of adequate visualisation, poly(L-lactic acid) microspheres loaded with holmium-166 ( ${ }^{166} \mathrm{Ho}$-PLLA-MS) have been developed [16-19]. Like ${ }^{90} \mathrm{Y},{ }^{166} \mathrm{Ho}$ is a high-energy betaemitter, but it emits low-energy gamma photons as well (Table 1), allowing for quantitative SPECT analysis and consequently dosimetric analysis [20]. Because holmium is also highly paramagnetic, the (intrahepatic) distribution of the ${ }^{166}$ Ho-PLLA-MS can be assessed through magnetic resonance imaging (MRI) as well $[21,22]$. In addition, instead of ${ }^{99 \mathrm{~m}}$ Tc-MAA, a small scout dose of ${ }^{166}$ Ho-PLLA-MS could be utilised to predict the biodistribution of the treatment dose of ${ }^{166}$ Ho-PLLA-MS.

In this article, the concept of a small scout dose of ${ }^{166} \mathrm{Ho}-$ PLLA-MS employed to predict the biodistribution of the therapeutic dose of ${ }^{166} \mathrm{Ho}$-PLLA-MS is investigated in the porcine model. The applicability of multimodal imaging (gamma scintigraphy, X-ray computed tomography (CT) and MRI) is also investigated. The accuracy of quantitative ${ }^{166}$ Ho SPECT analysis for heterogeneous distribution is also validated.

\section{Materials and methods}

\section{Animals}

Five healthy female pigs ( $8-9$ months old, weighing $70-75 \mathrm{~kg}$ ) were acquired from the Animal Sciences Group, Wageningen University and Research Centre, Lelystad, the Netherlands. A 2-week acclimatisation period was allowed. The experiments were conducted in agreement with the local applicable Dutch law, "Wet op de dierproeven" (art. 9) (1977), and the European Convention for the Protection of Vertebrate Animals used for Experimental and Other Scientific Purposes (1986), and approved by the ethics committee for animal experimentation of the University Medical Centre Utrecht, Utrecht, the Netherlands (DECABC-no. 2007.III.07.092).

\section{Microsphere preparation}

${ }^{165}$ Ho-PLLA-MS were prepared as previously described [17] (scout dose $60 \mathrm{mg}$; 'treatment dose' $540 \mathrm{mg}$ ) and packed in custom-made high-density polyethylene (HDPE) vials (Fig. 1) and neutron activated in the nuclear reactor of the Delft University of Technology (Delft, the Netherlands). Upon delivery at the hospital, two incompletely predrilled holes in the vial cover were perforated by needles $(19 \mathrm{G} \times$ $50 \mathrm{~mm}$ ), and the microspheres were suspended in $2 \mathrm{ml}$ of water for injection containing 2\% Pluronic ${ }^{\mathbb{R}}$ F-68 (SigmaAldrich Chemie B.V., Zwijndrecht, the Netherlands) and $10 \%$ absolute ethanol (Merck B.V., Amsterdam, the Netherlands). The cover of the vial was then removed and a tiny amount of ${ }^{166}$ Ho-PLLA-MS (ca. $1 \mathrm{mg}$ ) was taken out for quality control (by light microscopy) [23]. Next, a vial cover fitted with a PTFE/silicone septum (Sigma-Aldrich Chemie

Table 1 Characteristics of the microparticles

\begin{tabular}{|c|c|c|c|c|}
\hline & $\begin{array}{l}\text { SIR-Spheres } \\
\text { (SIRTeX Medical Ltd.) }\end{array}$ & $\begin{array}{l}\text { TheraSphere } \\
\text { (MDS Nordion Inc.) }\end{array}$ & $\begin{array}{l}{ }^{99 \mathrm{~m}} \text { Tc-MAA (Technescan } \\
{ }^{\circledR} \\
\text { LyoMAA, Mallinckrodt Medical Inc.) }\end{array}$ & $\begin{array}{l}{ }^{166} \text { Ho-PLLA-MS } \\
\text { (UMC Utrecht) }\end{array}$ \\
\hline Radionuclide & ${ }^{90} \mathrm{Y}$ & & ${ }^{99 \mathrm{~m}} \mathrm{Tc}$ & ${ }^{166} \mathrm{Ho}$ \\
\hline$\beta^{-}$emission $(\mathrm{MeV})$ & $2.28(100 \%)$ & & No $\beta$ emission & $\begin{array}{l}1.77(49 \%) \\
1.85(50 \%)\end{array}$ \\
\hline$\gamma$ emission $(\mathrm{keV})$ & No $\gamma$ emission & & $141 \mathrm{keV}(89 \%)$ & $80.6(6.7 \%)$ \\
\hline Matrix material & Resin & Glass & Aggregated human serum albumin & PLLA \\
\hline Density $(\mathrm{g} / \mathrm{ml})$ & $1.6[29]$ & $3.2[29]$ & $1.1[30]$ & 1.4 \\
\hline Diameter $(\mu \mathrm{m})$ & $32 \pm 10[29]$ & $25 \pm 10[29]$ & $10-60[11]$ & $30 \pm 5$ \\
\hline Administered number of particles & $50,000,000[7]$ & $4,000,000[7]$ & $150,000[11]$ & $33,000,000$ \\
\hline
\end{tabular}


Fig. 1 Schematic of the custom-made administration system for clinical application, which consists of the following components: iodine contrast agent (1), saline solution (2), 20-ml syringe (Luer-Lock) (3), three-stopcock manifold (4), one-way valve (5), inlet line (6), administration vial containing the ${ }^{166}$ Ho-PLLA-MS (7), outlet line (8), flushing line (9), Y-connector (10) and catheter (11). Not shown in this diagram is the lead-glass vial shield in which the HDPE vial is placed to limit the radiation dose to which the personnel are exposed

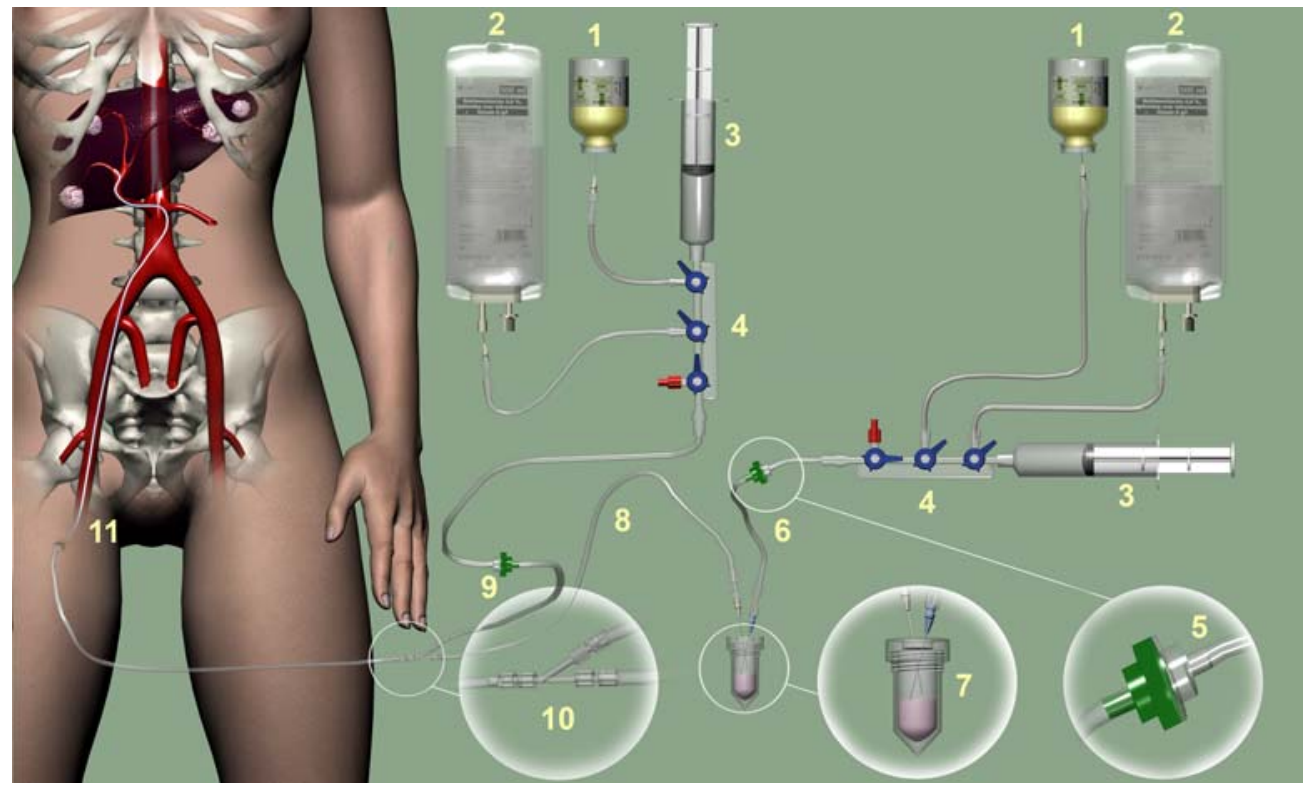

B.V., Zwijndrecht, the Netherlands) was screwed on top of the vial which was punctured by two needles $(19 \mathrm{G} \times 50 \mathrm{~mm})$. The amounts of radioactivity were measured in a dose calibrator (VDC-404, Veenstra Instrumenten B.V., Joure, the Netherlands). In order to prevent pile up and dead-time effects in the gamma camera, both the scout dose and the treatment dose consisted of $250 \mathrm{MBq}{ }^{166} \mathrm{Ho}$ at the time of injection.

\section{Anaesthesia and analgesia}

Premedication consisted of azaperone $(4 \mathrm{mg} / \mathrm{kg})$, ketamine hydrochloride $(10 \mathrm{mg} / \mathrm{kg})$ and atropine $(0.1 \mathrm{mg} / 10 \mathrm{~kg})$ intramuscular (IM). General anaesthesia was induced by intravenous administration (IV) of propofol $(2.5-3.5 \mathrm{mg} / \mathrm{kg}$ ) and maintained by propofol $(8-9 \mathrm{mg} / \mathrm{kg} / \mathrm{h})$ or inhalation of isoflurane $(1.5-2.0 \%)$ in $\mathrm{O}_{2} /$ air $(1: 1)$, in combination with midazolam hydrochloride $(0.2 \mathrm{mg} / \mathrm{kg}) \mathrm{IV}$. Perioperative analgesia was provided by sufentanil (loading dose $5 \mu \mathrm{g} / \mathrm{kg}$, maintenance dose $10 \mu \mathrm{g} / \mathrm{kg} / \mathrm{h}$ ) IV.

\section{Administration system}

A custom-made administration system was used (Fig. 1) that consisted of polyethylene tube lines equipped with one-way valves (Medisize B.V., Hillegom, the Netherlands) preventing backflow of microspheres in the lines. The lines were interconnected using a Y-connector (World Precision Instruments Inc., Sarasota, FL, USA). The system was connected to the catheter. To reduce the radiation dose to personnel the vial containing the ${ }^{166} \mathrm{Ho}-$ PLLA-MS was placed in a high-density lead-glass vial shield.
Angiography and microsphere administration procedure

A right femoral artery puncture was made and an Avanti $^{\circledR}+$ sheath $(7 \mathrm{~F}$, Cordis Europe N.V., Roden, the Netherlands) was introduced. Under fluoroscopic guidance, the common hepatic artery was catheterised and the exact anatomy of its branches was mapped out. Standard diagnostic $4 \mathrm{~F}$ catheters and guide wires were used. The scout dose and treatment dose of ${ }^{166}$ Ho-PLLA-MS were flushed out of the vial and into the (straight tip) catheter, positioned in the proper hepatic artery, by injecting $40-60 \mathrm{ml}$ of a $50: 50$ mixture of saline and iodine contrast agent into the vial, under fluoroscopy guidance, at a rate of $0.5-1.0 \mathrm{ml} / \mathrm{s}$.

\section{Medical imaging protocols}

For registration purposes, multimodal markers, filled with $2 \mathrm{MBq}{ }^{99 \mathrm{~m}} \mathrm{Tc}$ each, were attached to the skin just cranially and caudally from the liver. In vivo planar nuclear imaging and SPECT imaging were performed directly after administration of the scout dose and after administration of the treatment dose. The nuclear images were acquired and the SPECT images reconstructed as was previously described [20]. CT was performed after the treatment dose was administered (tube voltage $120 \mathrm{kVp}$, current $400 \mathrm{mAs}$; Brilliance ${ }^{\circledR}$, Philips Healthcare, Best, the Netherlands). After termination with sodium pentobarbitone $(100-200 \mathrm{mg} / \mathrm{kg}) \mathrm{IV}$, MRI was performed, including $T_{1}, T_{2}$ and $T_{2}{ }^{*}$ protocols, using a 1.5-T clinical device (Achieva ${ }^{\circledR}$, Philips Healthcare, Best, the Netherlands), according to previously described protocols [22]. 


\section{SPECT analysis}

The distributions of the scout dose and of the 'total dose' (scout dose + treatment dose) were compared. After rigid registration and downsampling to a $32 \times 32 \times 32$ matrix (18.9-mm voxel size), scatter plots were generated of which regression analysis was done. The accuracy of quantitative SPECT was assessed in a realistic model, by comparing the distribution of a SPECT image with the planar images of a pig's liver, in which ${ }^{166}$ Ho-PLLA-MS (600 mg, $250 \mathrm{MBq}$ at time of acquisition) had been injected into the hepatic artery ex vivo. The liver was placed in a metal box, in which five 16-mm-diameter tubes were also placed. The box was filled with carboxymethyl cellulose (CMC) $(2.5 \%)$ and subsequently frozen at $-20^{\circ} \mathrm{C}$. Twentyfour hours later the tubes were removed and the remaining holes were filled with a ${ }^{166} \mathrm{Ho} / \mathrm{CMC}$ chloride solution as radioactive markers. The box was again placed in the freezer. After SPECT acquisition, the liver was cut into eight 6-mm-thick slices with a floor-model band saw and planar nuclear images were acquired of each slice. The planar images were combined into a 3D volume, which was registered to the SPECT image and resampled to the same (isotropic) voxel size, after which scatter plot analysis was performed. The markers were used for registration and normalisation of the slices.

\section{Results}

Angiography and microsphere administration procedure

Selective catheterisation of the hepatic artery was successfully performed in all five pigs. The ${ }^{166} \mathrm{Ho}-\mathrm{PLLA}-\mathrm{MS}$ were gradually flushed out of the administration vial in a controlled manner. Y-connectors of a diameter matching that of the tube lines were used which prevented lodging of the ${ }^{166}$ Ho-PLLA-MS in the system. Measurements showed that less than $1 \%$ of the radioactivity remained in the administration systems used in any of these experiments.

\section{SPECT analysis}

Visual analysis of the SPECT images revealed that in all animals the ${ }^{166}$ Ho-PLLA-MS had been deposited in the liver exclusively. Qualitatively, the intrahepatic radioactivity distributions according to the respective scout dose and 'total dose' images of four out of five animals seemed similar (Fig. 2a-h). This was not the case for the images of the fifth animal, which was caused by unintended catheter displacement between the administration of the scout dose and the treatment dose (Fig. 2i,j). Rigid registration and subsequent analysis of the SPECT images of the scout dose and total dose was feasible in two out of five animals. In one of these animals (the one in which the catheter was displaced between administrations) the relation between the scout dose distribution and total dose distribution was rather poor $\left(r^{2}=0.34\right)$, whereas in the other animal the relation was significantly better $\left(r^{2}=0.66\right)$ (Fig. 3).

Comparison by scatter plot analysis of planar nuclear images of slices of the ex vivo pig liver, combined into a 3D volume, with the SPECT image revealed a strong correlation between the SPECT and the planar images $\left(r^{2}=0.90\right)$ (Fig. 4).

\section{CT and MRI}

Relatively high concentrations of ${ }^{166}$ Ho-PLLA-MS present in hepatic arteries could be visualised by CT (Fig. 5a) Holmium-based artefacts could be observed on the $T_{2}{ }^{*}$-weighted MR images (Fig. 5b). The distribution of ${ }^{166}$ Ho-PLLA-MS observed on the MR images was quite similar to CT. A discrepancy was seen in liver regions containing lower concentrations of ${ }^{166}$ Ho-PLLA-MS. Relatively low concentrations still detectable by MRI were absent on the CT images.

\section{Discussion}

The characteristics of ${ }^{166} \mathrm{Ho}$-PLLA-MS could enable the use of a scout dose of ${ }^{166} \mathrm{Ho}$-PLLA-MS to predict the distribution of the therapeutic dose of ${ }^{166}$ Ho-PLLA-MS. In this study, this concept has been tested in a relatively anthropomorphic animal model, namely the domestic pig. Five pigs were successfully catheterised and a scout dose and a treatment dose were injected into the hepatic artery. The use of the dedicated neutron-activation/administration vial made pretreatment quality control of the ${ }^{166}$ Ho-PLLA-MS possible and prevented the need to transfer radioactivity from a neutron activation vial to an administration vial. The tube lines in the systems supplied by the manufacturers of the glass and resin microspheres are connected using standard three-way stopcocks. It is reported that ${ }^{90} \mathrm{Y}-\mathrm{MS}$ tend to be retained in and just before the stopcock [24]. Loosening up the jammed microspheres requires tapping and/or gently shaking of the stopcock. In the presently used system this lodging of microspheres did not occur because, instead of stopcocks, Y-connectors of a diameter matching that of the tube lines were used. Administration of the ${ }^{166}$ Ho-PLLA-MS suspended in a mixture of saline and iodine contrast agent permitted immediate observation of stasis and/or backflow and timely interruption of the procedure.

Preclinical research has also been conducted by other groups on the development of microspheres that mimic ${ }^{90} \mathrm{Y}-\mathrm{MS}$ better than the ${ }^{99 \mathrm{~m}} \mathrm{Tc}-\mathrm{MAA}$, and which, like ${ }^{166}$ Ho-PLLA-MS, possess high quality imaging possibilities. Recently proposed substitutes for the glass ${ }^{90} \mathrm{Y}-\mathrm{MS}$ were iron-labelled glass-ceramic microspheres [12]. In Vx2 
Fig. 2 Planar nuclear images (anterior view) of the pigs acquired after administration into the hepatic artery of the scout dose of ${ }^{166}$ Ho-PLLA-MS

(60 mg, $250 \mathrm{MBq})$ (a, c, e, g, i), and planar nuclear images

acquired from the total dose,

which constitutes the scout dose and the subsequently

administered 'treatment dose' of

${ }^{66}$ Ho-PLLA-MS $(540 \mathrm{mg}$, $250 \mathrm{MBq})(\mathbf{b}, \mathbf{d}, \mathbf{f}, \mathbf{h}, \mathbf{j})$

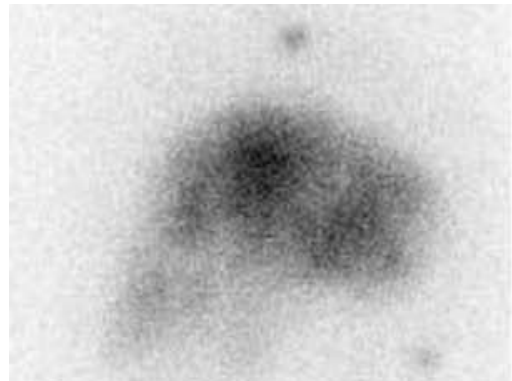

a

b

c

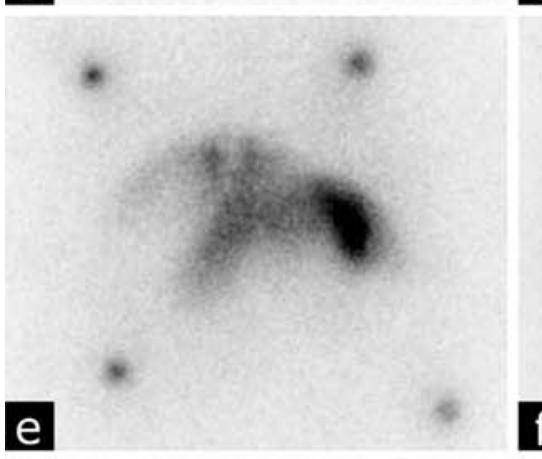

g

h

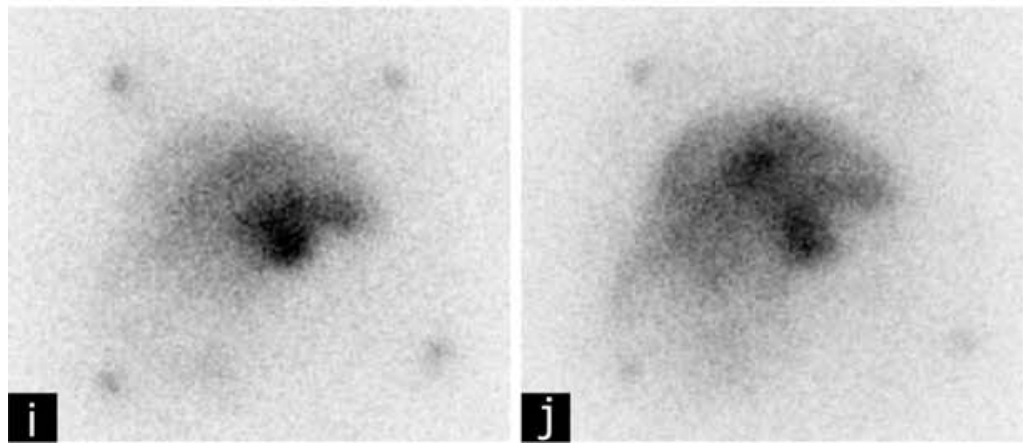




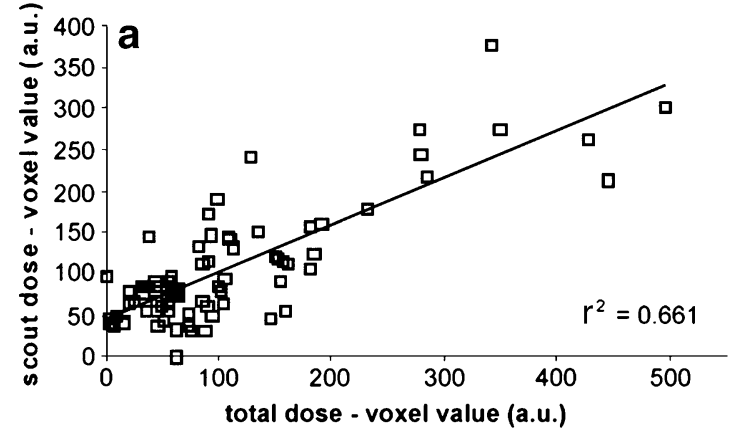

Fig. 3 Scatter plots obtained from the SPECT images of two pigs, in which the distribution of the respective scout dose and total dose were compared. In one animal the relation between the scout dose

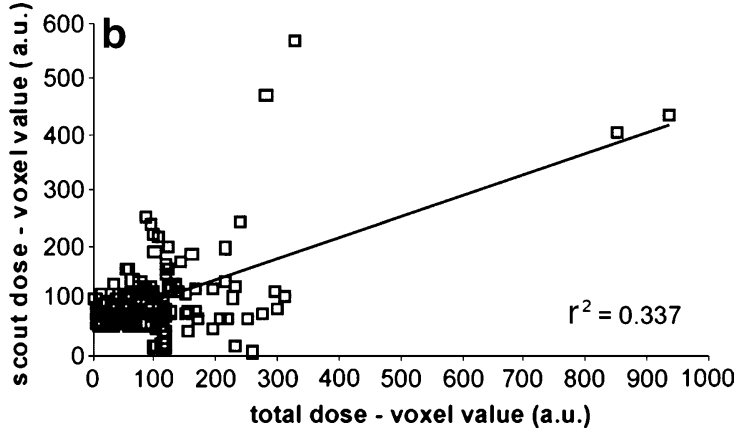

and the total dose was quite good (a), whereas in the other animal the relation between the scout dose and the total dose was rather poor (b) a

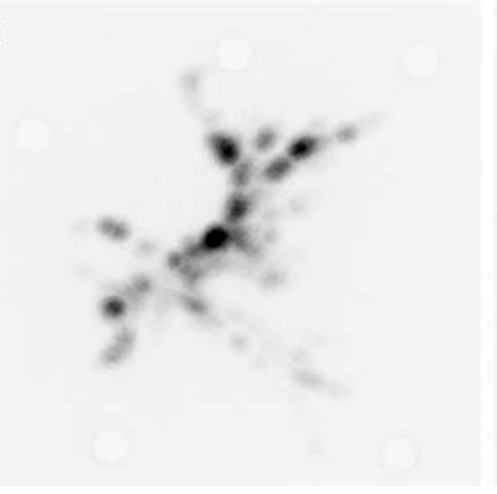

Fig. 4 Maximum intensity projections of the stacked planar nuclear images acquired from an ex vivo pig liver (a) and of the SPECT image of this liver (b). Quantification of the SPECT images using b

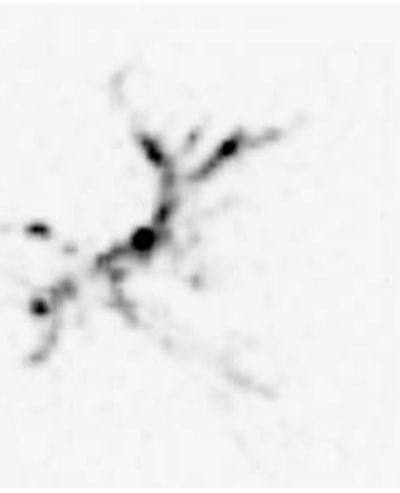

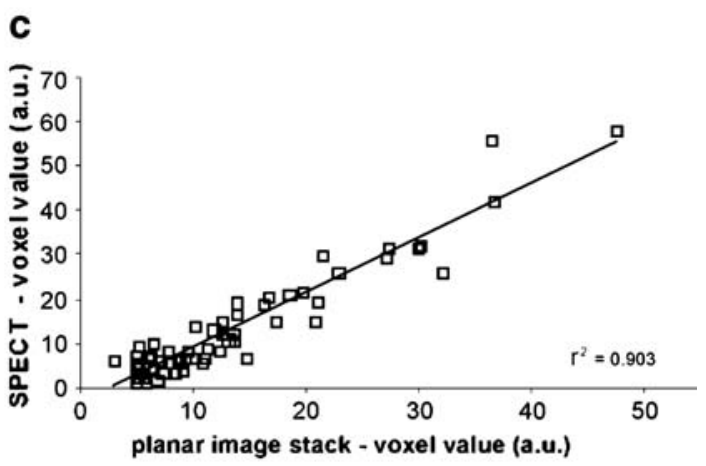

hybrid scatter correction demonstrated that the radioactivity distribution according to the SPECT images was highly similar to the distribution based on the planar images (c)

Fig. $5{ }^{166}$ Ho-PLLA-MS visualised by $\mathrm{CT}$ maximum intensity projection (a), and by $T_{2}{ }^{*}$-weighted MRI (8-mm slice) (b). High concentrations are indicated by circles
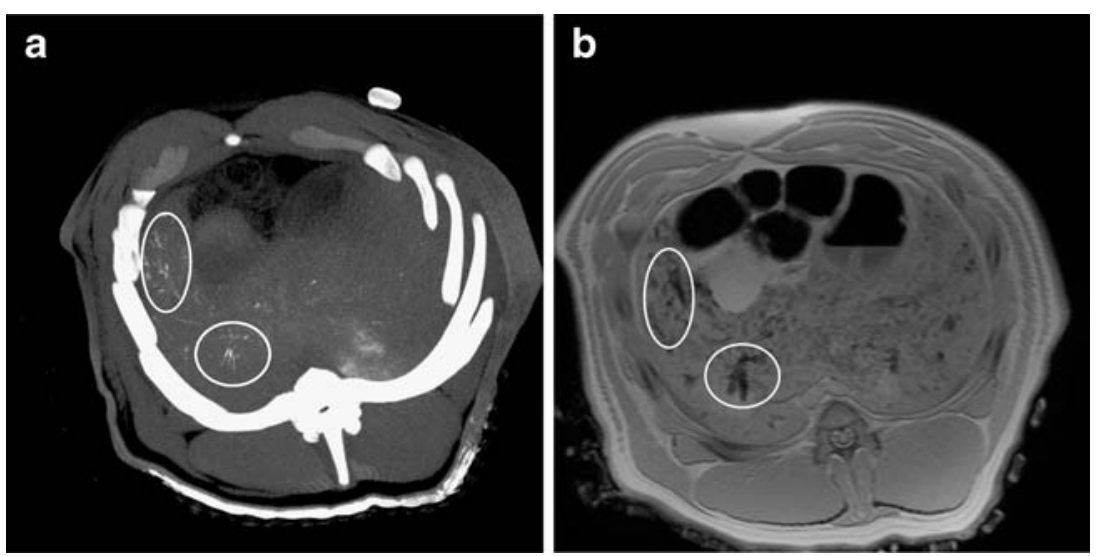
carcinoma-bearing rabbits, it was demonstrated that these iron-labelled particles can be visualised in real time by MRI. Resin microspheres labelled with fluorine-18 $\left({ }^{18} \mathrm{~F}\right)$ allowing for positron emission tomography were proposed to serve as surrogates for the resin ${ }^{90} \mathrm{Y}$-MS [25]. These ${ }^{18} \mathrm{~F}$ microspheres may also enable accurate assessment of the biodistribution of the treatment dose when co-injected with the resin ${ }^{90} \mathrm{Y}$-MS. Regarding both the iron-labelled glassceramic microspheres and the ${ }^{18} \mathrm{~F}$ resin microspheres, extensive preclinical research is warranted before clinical application will be allowed.

${ }^{166} \mathrm{Ho}$ is a true multimodal agent, allowing for visualisation by gamma scintigraphy, MRI and CT. The sensitivity of CT for holmium is relatively low; compared with SPECT its sensitivity is $2-3$ orders of magnitude lower, and approximately 20 times lower than that of MRI [26]. It is therefore expected that $\mathrm{CT}$ is too insensitive to allow reliable biodistribution assessment of a scout dose of $60 \mathrm{mg}$ of ${ }^{166}$ Ho-PLLA-MS. MRI was able to detect ${ }^{166} \mathrm{Ho}-\mathrm{PLLA}-$ MS at lower concentrations than CT, which was supported by previously reported results [26, 27]. As MRI provides detailed anatomic imaging as well, this technique is thought to be especially useful in dynamic imaging of ${ }^{166}$ Ho-PLLA-MS accumulating in and around tumours, and could provide real-time monitored (supra)selective administration of ${ }^{166} \mathrm{Ho}$-PLLA-MS [28]. For its high sensitivity SPECT is currently the best-suited imaging technique for visualisation of both the scout dose and the treatment dose of ${ }^{166} \mathrm{Ho}$-PLLA-MS. For safety and efficacy purposes individualised dose calculation is required. To this end pretreatment tumour and liver dosimetry is a prerequisite. Dosimetry entails quantitative SPECT analy- sis which was validated for a distinctly inhomogeneous distribution of ${ }^{166} \mathrm{Ho}$-PLLA-MS in this study. The methodology described in this paper is aimed at improving clinical results of radioembolisation in patients with unresectable liver tumours. Confirmation of the clinical applicability of this concept has to be established in upcoming patient studies.

\section{Conclusions}

In non-tumour-bearing pigs, a scout dose of ${ }^{166} \mathrm{Ho}$-PLLAMS can accurately predict the biodistribution of a treatment dose of ${ }^{166}$ Ho-PLLA-MS, as assessed by qualitative and quantitative SPECT. MRI can accurately visualise low concentrations of ${ }^{166} \mathrm{Ho}$-PLLA-MS. Quantitative ${ }^{166} \mathrm{Ho}$ SPECT, necessary for dosimetric analysis, was validated in a realistic model. The custom-made administration system and neutron-activation/administration vial was tested as well and found satisfactory for the neutron activation and the administration of ${ }^{166}$ Ho-PLLA-MS.

Acknowledgements Financial support by the Dutch Technology Foundation STW under grant UGT.6069 is gratefully acknowledged. The authors would also like to thank Mr. Simon Plomp for his assistance in the preparation of the liver slices, and Mr. Remmert de Roos for his assistance in the preparation of the microspheres.

Open Access This article is distributed under the terms of the Creative Commons Attribution Noncommercial License which permits any noncommercial use, distribution, and reproduction in any medium, provided the original author(s) and source are credited.

\section{References}

1. Gulec SA, Fong Y (2007) Yttrium 90 microsphere selective internal radiation treatment of hepatic colorectal metastases. Arch Surg 142:675-682

2. Salem R, Thurston KG (2006)

Radioembolization with yttrium-90 microspheres: a state-of-the-art brachytherapy treatment for primary and secondary liver malignancies: part 3: comprehensive literature review and future direction. J Vasc Interv Radiol 17:1571-1593

3. Breedis C, Young G (1954) The blood supply of neoplasms in the liver. Am J Pathol 30:969-977
4. Bierman HR, Byron RL Jr, Kelley KH, Grady A (1951) Studies on the blood supply of tumors in man. III. Vascular patterns of the liver by hepatic arteriography in vivo. J Natl Cancer Inst 12:107-131

5. Salem R, Thurston KG (2006) Radioembolization with 90yttrium microspheres: a state-of-the-art brachytherapy treatment for primary and secondary liver malignancies. Part 1: technical and methodologic considerations. J Vasc Interv Radiol 17:1251-1278

6. Leung WT, Lau WY, Ho SKW, Chan M, Leung NWY, Lin J, Metreweli C, Johnson PJ, Li AKC (1994) Measuring lung shunting in hepatocellular carcinoma with intrahepatic-arterial technetium-99m macroaggregated albumin. J Nucl Med 35:70-73
7. Murthy R, Nunez R, Szklaruk J, Erwin W, Madoff DC, Gupta S, Ahrar K, Wallace MJ, Cohen A, Coldwell DM, Kennedy AS, Hicks ME (2005) Yttrium-90 microsphere therapy for hepatic malignancy: devices, indications, technical considerations, and potential complications. Radiographics 25(Suppl 1):S41-S55

8. Ho S, Lau WY, Leung TW, Johnson PJ (1998) Internal radiation therapy for patients with primary or metastatic hepatic cancer: a review. Cancer 83:1894-1907 
9. Ho S, Lau WY, Leung TW, Chan M, Ngar YK, Johnson PJ, Li AK (1996) Partition model for estimating radiation doses from yttrium-90 microspheres in treating hepatic tumours. Eur J Nucl Med 23:947-952

10. Leung TW, Lau WY, Ho SK, Chan M, Leung NW, Lin J, Metreweli C, Johnson PJ, Li AK (1994) Determination of tumour vascularity using selective hepatic angiography as compared with intrahepatic-arterial technetium-99m macroaggregated albumin scan in hepatocellular carcinoma. Cancer Chemother Pharmacol 33(Suppl):S33-S36

11. Koch W, Tatsch K (2008) Nuclear medicine procedures for treatment evaluation. In: Bilbao JI, Reiser MF (eds) Liver radioembolization with $90 \mathrm{Y}$ microspheres, 1st edn. Springer, Heidelberg, pp 75-91

12. Gupta T, Virmani S, Neidt TM, Szolc-Kowalska B, Sato KT, Ryu RK, Lewandowski RJ, Gates VL, Woloschak GE, Salem R, OMary RA, Larson AC (2008) MR tracking of iron-labeled glass radioembolization microspheres during transcatheter delivery to rabbit VX2 liver tumors: feasibility study. Radiology 249:845-854

13. Dhabuwala A, Lamerton P, Stubbs RS (2005) Relationship of 99mtechnetium labelled macroaggregated albumin (99mTc-MAA) uptake by colorectal liver metastases to response following selective internal radiation therapy (SIRT). BMC Nucl Med 5:7

14. Sarfaraz M, Kennedy AS, Lodge MA, Li XA, Wu X, Yu CX (2004) Radiation absorbed dose distribution in a patient treated with yttrium-90 microspheres for hepatocellular carcinoma. Med Phys 31:2449-2453

15. Sandström M, Lubberink M, Lundquist H (2005) Quantitative SPECT with Yttrium-90 for radionuclide therapy dosimetry. Eur J Nucl Med Mol Imaging 32:S260
16. Vente MAD, Nijsen JFW, De Wit TC, Seppenwoolde JH, Krijger GC, Seevinck PR, Huisman A, Zonnenberg BA, Van den Ingh TSGAM, Van het Schip AD (2008) Clinical effects of transcatheter hepatic arterial embolization with holmium-166 poly (L-lactic acid) microspheres in healthy pigs. Eur J Nucl Med Mol Imaging 35:1259-1271

17. Zielhuis SW, Nijsen JFW, De Roos R, Krijger GC, Van Rijk PP, Hennink WE, Van het Schip AD (2006) Production of GMP-grade radioactive holmium loaded poly(l-lactic acid) microspheres for clinical application. Int J Pharm 311:69-74

18. Nijsen JFW, Van Steenbergen MJ, Kooijman H, Talsma $\mathrm{H}$ Kroon-Batenburg LMJ, Van de Weert M, Van Rijk PP, De Witte A, Van het Schip AD, Hennink WE (2001) Characterization of poly(L-lactic acid) microspheres loaded with holmium acetylacetonate. Biomaterials 22:3073-3081

19. Nijsen JFW, Zonnenberg BA, Woittiez JR, Rook DW, Swildens-Van Woudenberg IA, Van Rijk PP, Van het Schip AD (1999) Holmium-166 poly lactic acid microspheres applicable for intra-arterial radionuclide therapy of hepatic malignancies: effects of preparation and neutron activation techniques. Eur J Nucl Med 26:699704

20. De Wit TC, Xiao J, Nijsen JF, Van het Schip AD, Staelens SG, Van Rijk PP, Beekman FJ (2006) Hybrid scatter correction applied to quantitative holmium-166 SPECT. Phys Med Biol 51:4773-4787

21. Seppenwoolde JH, Nijsen JFW, Bartels LW, Zielhuis SW, Van het Schip AD, Bakker CJ (2004) Internal radiation therapy of liver tumors: qualitative and quantitative magnetic resonance imaging of the biodistribution of holmiumloaded microspheres in animal models. Magn Reson Med 53:76-84

22. Nijsen JFW, Seppenwoolde JH, Havenith T, Bos C, Bakker CJG, Van het Schip AD (2004) Liver tumors: MR imaging of radioactive holmium microspheres-phantom and rabbit study. Radiology 231:491-499

23. Vente MA, Nijsen JF, De Roos R, Van Steenbergen MJ, Kaaijk CN, Koster-Ammerlaan MJ, De Leege PF, Hennink WE, Van het Schip AD, Krijger GC (2009) Neutron activation of holmium poly(L-lactic acid) microspheres for hepatic arterial radioembolization: a validation study. Biomed Microdevices 11(4):763-72
24. Salem R, Thurston KG, Carr BI, Goin JE, Geschwind JF (2002) Yttrium-90 microspheres: radiation therapy for unresectable liver cancer. J Vasc Interv Radiol 13:S223-S229

25. Selwyn RG, Avila-Rodriguez MA, Converse AK, Hampel JA, Jaskowiak CJ, McDermott JC, Warner TF, Nickles RJ, Thomadsen BR (2007) 18F-labeled resin microspheres as surrogates for $90 \mathrm{Y}$ resin microspheres used in the treatment of hepatic tumors: a radiolabeling and PET validation study. Phys Med Biol 52:7397-7408

26. Seevinck PR, Seppenwoolde JH, de Wit TC, Nijsen JF, Beekman FJ, Van het Schip AD, Bakker CJ (2007) Factors affecting the sensitivity and detection limits of MRI, CT, and SPECT for multimodal diagnostic and therapeutic agents. Anticancer Agents Med Chem 7:317-334

27. Seevinck PR, Bult W, Nijsen JFW, Vente MAD, De Roos R, Van het Schip AD, Bakker CJG (2008) Highly-loaded holmium microspheres for test dose detection and biodistribution prediction in internal radiation therapy of liver tumors. International Society for Magnetic Resonance in Medicine 274

28. Seppenwoolde JH, Bartels LW, Van der Weide R, Nijsen JFW, Van het Schip AD, Bakker CJ (2006) Fully MRguided hepatic artery catheterization for selective drug delivery: a feasibility study in pigs. J Magn Reson Imaging 23:123-129

29. Kennedy AS, Nutting C, Coldwell D et al (2004) Pathologic response and microdosimetry of (90)Y microspheres in man: review of four explanted whole livers. Int J Radiat Oncol Biol Phys 60:1552-1563

30. Rao SN, Basu SP, Sanny CG et al (1976) Preliminary x-ray investigation of an orthorhombic crystal form of human plasma albumin. J Biol Chem 251:3191-3193 